\title{
Tear film osmolarity and dry eye disease: a review of the literature
}

This article was published in the following Dove Press journal:

Clinical Ophthalmology

2 November 2015

Number of times this article has been viewed

\section{Richard Potvin' \\ Sarah Makari ${ }^{\prime}$ \\ Christopher J Rapuano² \\ 'Science in Vision, Akron, NY, USA; ${ }^{2}$ Wills Eye Hospital, Philadelphia, PA, USA}

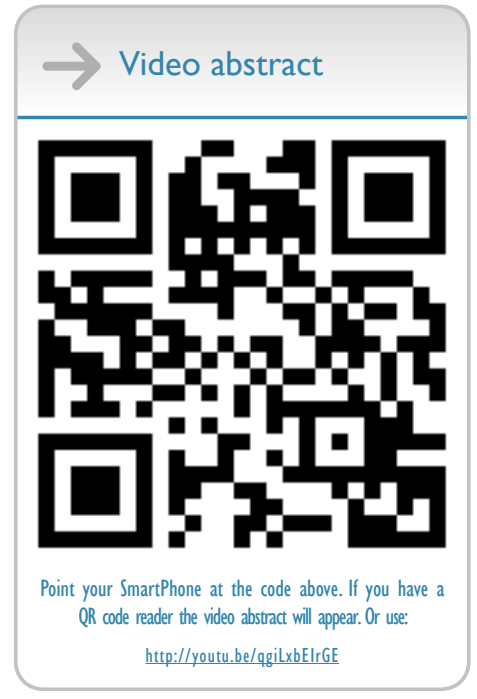

Correspondence: Richard Potvin Science in Vision, 6197 Dye Road, Akron, NY, USA I400I

Tel +l 4076976008

Fax + 7164425110

Email rick@scienceinvision.com
Objective: To evaluate the evidence in the peer-reviewed literature regarding the use of tear osmolarity as a physiological marker to diagnose, grade severity, and track therapeutic response in dry eye disease (DED). In addition, to review the evidence for the role of tear osmolarity in the pathophysiology of DED and ocular surface disease.

Methods: A literature review of all publications after the year 2000, which included the keywords "tear osmolarity", was conducted. Relevant articles were graded according to quality of evidence and research, using the University of Michigan Practice Guideline and the Grading of Recommendations Assessment, Development, and Evaluation (GRADE) rating systems. Articles were further categorized by the nature of any reported financial support and by the overall impression they provided related to tear osmolarity.

Results: A total of 164 articles were identified as relevant to the search criteria, although some were editorials, and some were written in a foreign language. Of the total, it was possible to grade 159, and an overall impression was generated for 163. A positive impression of tear osmolarity in DED diagnosis was evident in $72 \%$ (117/163) of all articles, with a neutral impression in a further $21 \%(35 / 163) ; 7 \%$ had a negative impression. The percentage of positive impressions appeared independent of the quality of research; 73\% (38/52) of articles graded high/moderate quality supported the use of tear film osmolarity measurement in DED diagnosis. Impressions were also independent of the source of financial support, with $72 \%(75 / 104)$ of independent studies positive.

Conclusion: The literature broadly supports the use of tear film osmolarity as an objective numerical measure for diagnosing, grading severity, and managing treatment of DED.

Keywords: TearLab, osmometer, keratoconjunctivitis sicca, dry eye diagnosis

\section{Introduction}

Dry eye disease (DED) continues to present clinicians with a diagnostic dilemma, primarily due to its multiple causative factors. As a result of the disease's complexity, there is currently no test or set of tests considered a "gold standard" for its diagnosis and monitoring. Without such a diagnostic standard of care, DED testing and/or treatment is often not performed until a patient is symptomatic. However, a recent study showed that $43 \%$ of asymptomatic patients had clinical signs of dry eyes. ${ }^{1}$ If left untreated, DED can significantly impact a person's vision and quality of life. A diagnostic tool that can globally diagnose DED, regardless of the cause, may be valuable in helping physicians establish an earlier and more accurate dry eye diagnosis.

Based on the definition from the dry eye workshop (DEWS) in 2007, DED is defined as follows:

Dry eye is a multifactorial disease [........ that results in symptoms of discomfort, visual disturbance, and tear film instability with potential damage to the ocular surface. It is 
accompanied by increased osmolarity of the tear film and inflammation of the ocular surface. ${ }^{2}$

As can be seen from the definition, the symptoms are likely non-specific, and ocular surface damage may actually be a late complication. The DEWS identified increased tear osmolarity and tear film instability as "core mechanisms" of DED, regardless of the etiology. ${ }^{2}$ Tests that accurately measure tear osmolarity and tear film instability should therefore, theoretically be best for identifying and determining the severity of DED. Tear osmolarity is attractive, because it offers an objective numerical output that can be monitored; other commonly used diagnostic tests rely heavily on subjective grading criteria.

In the past, the two most commonly used instruments to measure tear osmolarity were the Clifton and vapor pressure osmometers. Studies have demonstrated their accuracy, high sensitivity and specificity. ${ }^{3,4}$ The main downside to these instruments is that they require a significant amount of time and involve numerous steps, increasing the potential for tear evaporation; as such, they are not practical, especially for dry eye patients with low tear volumes. ${ }^{3,4}$ A newer technology produced by TearLab uses a micro-electrode to measure the number of charged particles in a tear sample; this electrode is designed to avoid direct contact with the ocular surface, thereby reducing the chance for reflex tearing. ${ }^{3}$ The TearLab measurement method appears as accurate as the more involved osmometers, differing on average by only $2 \mathrm{mOsm} / \mathrm{L}$ in both normal and dry eye patients. ${ }^{3}$ The TearLab device requires only a small tear sample $(\sim 0.2 \mu \mathrm{L})$ and is able to provide results almost instantly, reducing the level of tear evaporation., ${ }^{3,5}$ When compared with a vapor pressure osmometer, the TearLab Osmolarity System was able to measure more patients with lower volume tear samples. ${ }^{4}$ Compared to the Clifton osmometer, the TearLab device was reported to have similar sensitivity but slightly better specificity and positive predictive value. ${ }^{3}$

The aim of the current review is to establish whether published studies support the use of tear osmolarity testing, primarily using the TearLab device, as a tool for DED diagnosis and treatment monitoring. Comments from the literature related to the role of tear osmolarity in the pathophysiology of DED and how ocular or systemic conditions and pharmaceuticals impact tear osmolarity are also discussed.

\section{Methods}

A literature search was conducted using PubMed in June 2014, using the search term "tear osmolarity" to identify all potentially relevant articles to that date. A review of the abstract of each article was used to identify those related or unrelated to tear osmolarity, or to identify those articles where tear osmolarity was not a primary focus of the paper. Where there was any doubt, the paper was classified as related to tear osmolarity. A more detailed review of the remaining papers related to tear osmolarity was then conducted to better categorize their contents. Tear osmolarity research before the year 2000 was limited in scope, methodology, and applicability. More recent research generally reflects any relevant earlier results, so a decision was made that articles published in the year 1999 or earlier would not be included in the review. Discussions of tear osmolarity that did not include a diagnostic component were also eliminated; while they provide a research basis for the use of osmolarity in evaluating the tear film, diagnostic papers are indicative of the clinical application of this more basic research.

A rating of all relevant articles was performed using the Grading of Recommendations Assessment, Development and Evaluation (GRADE) which is based on the likelihood that further research is required to confirm the significance of reported results, ${ }^{6}$ as well as the University of Michigan Practice Guideline which is based on the study design. ${ }^{7}$ The GRADE scoring included consideration of both study sample size and financial interest disclosures in evaluating the "quality" of the evidence. The financial interest categorization was not to suggest that sponsored studies are lower quality than independent research, but only to reflect the potential for bias in reporting results. Relevant data were entered into an Access database (Microsoft Corporation, Redmond, WA, USA) for analysis.

An article was rated in the "high" category if it fulfilled both the A criteria in the University of Michigan Practice Guideline and fulfilled the definition in the "high" requirement under the GRADE system. Similarly, B and "moderate", C and "low", as well as D and "very low" were used from the University of Michigan Practice Guideline and the GRADE rating systems, respectively, to identify the rating of the relevant articles. The final grade was the lower rank based on the two grading systems. The articles were also subjectively reviewed for the impression they left with the reader, whether "positive", "neutral", or "negative" with regard to the diagnostic utility of tear osmolarity.

\section{Results}

Table 1 contains the summary of preliminary search data; a total of 407 articles were listed as potentially relating to tear osmolarity. The results from this preliminary analysis identified 164 papers in the peer-reviewed literature as having some reference to tear osmolarity and its use as a diagnostic tool. 
Table I Results of initial search of PubMed database, and subsequent review (conducted June Ist, 20I4, using PubMed online)

\begin{tabular}{lll}
\hline Topic & Number of articles & Remaining articles \\
\hline "Tear osmolarity" in any search field (title, abstract, and keywords) & 407 & 407 \\
Articles older than year 2000 (deemed too old to be relevant) & 136 & 271 \\
Articles did not focus on use of tear osmolarity as a diagnostic tool & 107 & 164 \\
\hline
\end{tabular}

Of the 164 articles identified as relevant peer-reviewed articles, an impression of the results (positive/neutral/ negative) was possible for 163 of them (one foreign language study was excluded). All but four of the remaining studies could be graded as well, using the combination of the two grading systems outlined previously.

Table 2 shows the breakdown of articles by grading and impression. As can be seen, only 32\% (52/163) of the studies available qualified as moderate or high quality; sample size, a lack of randomization, and the lack of control populations were the primary limiting design factors that led to lower quality ratings for studies. In this subgroup of moderate or high quality articles, $73 \%(38 / 52)$ had a positive impression, $17 \%$ had a neutral impression, and $10 \%$ had a negative impression. This breakdown by impression was similar to that for the studies graded low or very low (71\% positive, $24 \%$ neutral, and $5 \%$ negative, respectively).

Table 3 summarizes the financial interest breakdown, with a percentage breakdown in each financial interest column. Approximately two-thirds of the articles were independent, with the remaining third sponsored (by TearLab or others). All the corporate-sponsored studies/articles had a positive impression. The impressions for $93 \%$ of the much larger group of independent articles were positive or neutral. While not shown in Table 3, the results were independent of study quality; of the 104 independent studies that were rated, $31 \%(32 / 104)$ had a high or moderate rating, and of those 32 articles, $72 \%$ (23/32) were positive, indicating that tear osmolarity was a useful diagnostic tool in the evaluation of dry eye and its severity. A further 19\% (6/32) were neutral, while $9 \%(3 / 32)$ of the articles suggested there was little value to the use of tear osmolarity.

The following discussion outlines the results of the literature review based primarily on studies rated as moderate or high. We discuss how tear osmolarity testing is performed, the cut-off value for dry eye diagnosis, the accuracy and repeatability of tear osmolarity testing, and how tear osmolarity compares with other commonly used diagnostic tests. Finally, articles discussing the effect of external factors, ocular and/or systemic disease, and pharmaceuticals on tear osmolarity are reviewed.

\section{Tear osmolarity as a diagnostic tool}

Evaluating the diagnostic ability of tear osmolarity requires specifying a value that discriminates a healthy eye from an eye with DED; this value is known as the threshold value. In the literature, tear osmolarity threshold values have varied from $305 \mathrm{mOsm} / \mathrm{L}^{8}$ to $316 \mathrm{mOsm} / \mathrm{L} .{ }^{5}$ One reported reason for variability in tear osmolarity threshold values is tear film instability, a hallmark characteristic of the disease. ${ }^{9,10}$ Normal, mild/moderate, and severe dry eyes had average tear osmolarity values of approximately $302+/-8 \mathrm{mOsm} / \mathrm{L}, 315+/-10 \mathrm{mOsm} / \mathrm{L}$ and $336+/ 022 \mathrm{mOsm} / \mathrm{L}$, respectively. ${ }^{10,11}$ Another study had lower reported mean values, but the study noted that they included more patients with mild and moderate DED than severe DED. ${ }^{8}$ It can be seen that the distribution of DED severity in different populations may explain some of the variability in threshold values. Studies have demonstrated that tear osmolarity is most influenced by, and correlated with, disease severity. ${ }^{10,11}$

One study found that using a tear osmolarity threshold of $305 \mathrm{mOsm} / \mathrm{L}$ gave a $98.4 \%$ positive predictive value. ${ }^{8} \mathrm{Using}$ a tear osmolarity threshold of $316 \mathrm{mOsm} / \mathrm{L}$ to $317 \mathrm{mOsm} / \mathrm{L}$, sensitivity varied from $59 \%{ }^{12}$ to $81 \%,{ }^{13}$ specificity varied from $78 \%{ }^{14}$ to $94 \%,{ }^{12}$ with a positive predictive value of $85 \%,{ }^{3,13}$ a negative predictive value of $74 \%,{ }^{13}$ and an overall predictive accuracy of $89 \%{ }^{12}$ A meta-analysis that used a $316 \mathrm{mOsm} / \mathrm{L}$ threshold noted that tear osmolarity may be more accurate than lactoplate, the Schirmer's test, and Rose Bengal testing. ${ }^{12}$ Currently, the $316 \mathrm{mOsm} / \mathrm{L}$ threshold is believed to better discriminate between mild and moderate/severe dry eye,

Table 2 Article quality rating by subjective impression

\begin{tabular}{llllll}
\hline Impression (n, \%) & High (n) & Moderate $(\mathbf{n})$ & Low $(\mathbf{n})$ & Very low (n) & Not rated (n) \\
\hline Positive $(117,72)$ & 3 & 35 & 73 & 3 & 3 \\
Neutral $(35,21)$ & 0 & 9 & 26 & 0 & 0 \\
Negative (II, 7) & 0 & 5 & 4 & 1 & 1 \\
\hline
\end{tabular}

Abbreviation: $\mathrm{n}$, number of articles. 
Table 3 Financial interest breakdown

\begin{tabular}{lllll}
\hline Impression (n, \%) & Independent $\mathbf{n}(\%)$ & TearLab n (\%) & Other $\mathbf{n}(\%)$ & Not stated/blank n (\%) \\
\hline Positive (II7, 72) & $75(72)$ & $12(100)$ & $12(63)$ & $18(64)$ \\
Neutral $(35,21)$ & $22(21)$ & 0 & $6(32)$ & $7(25)$ \\
Negative (II, 7) & $7(7)$ & 0 & $1(5)$ & $3(11)$ \\
\hline
\end{tabular}

Abbreviation: $\mathrm{n}$, number of articles.

while $308 \mathrm{mOsm} / \mathrm{L}$ is now considered to be a widely accepted threshold. ${ }^{5}$ A tear osmolarity threshold of $308 \mathrm{mOsm} / \mathrm{L}$ correctly diagnosed severe dry eye and normal patients $90.7 \%$ and $81.3 \%$ of the time, respectively; this value appeared to be the most sensitive for discriminating between normal eyes and those presenting with early stages of DED. ${ }^{10}$

Variability in tear osmolarity can also be a diagnostic indicator; in one study, variability between the two eyes in normal, mild, or moderate dry eye patients and severe dry eye patients was $6.9 \pm 5.9 \mathrm{mOsm} / \mathrm{L}, 11.7 \pm 10.9 \mathrm{mOsm} / \mathrm{L}$, and 26.5 $\pm 22.7 \mathrm{mOsm} / \mathrm{L}$, respectively. ${ }^{10}$ Variability in inter-eye measurements and repeat measurements in the same eye appears to increase with the severity of dry eye. Mild DED may also manifest as variability with repeat measurement of the same eye or between the two eyes. Measured osmolarity is low and stable in those without DED. ${ }^{9}$ Tear osmolarity has been shown to have good repeatability ${ }^{8}$ in normal subjects, with no significant difference in osmolarity values when using up to four readings taken 1 to 15 minutes apart. ${ }^{9}$

A concern with using osmolarity as a diagnostic test is the observed overlap in measured values between normal and dry eyes; this has been documented as especially high in two studies..$^{15,16}$ However, in one of these studies, ${ }^{15}$ dry eye patients were being treated with eye drops or systemic medications, which would be expected to lower osmolarity. The second study ${ }^{16}$ may have suffered from a "selection bias", where other diagnostic tests, but not tear osmolarity, were used to categorize patients into a dry eye and a control group. This categorization may have skewed the results in favor of the tests used in the categorization process. ${ }^{16}$ Different studies have suggested that tear osmolarity does not provide a sharp diagnostic cut-off, but rather can serve as a guide to indicate disease severity or progression. ${ }^{8,10}$

While tear osmolarity testing is beneficial at providing a numerical value to the current state of dry eyes, other complementary diagnostic tests are valuable in discriminating the etiology of the disease. ${ }^{10}$

\section{Tear osmolarity compared to other diagnostic tests}

When compared with Schirmer's test results, meibomian gland grading, Ocular Surface Disease Index ${ }^{\odot}$ (OSDI), tear break-up time (TBUT), corneal and conjunctival staining, tear osmolarity was better at predicting dry eye severity; as tear osmolarity increased, dry eye severity also increased in a largely linear pattern. ${ }^{8,11}$ Another study also demonstrated that tear osmolarity had higher sensitivity when compared with corneal staining, conjunctival staining, and meibomian grading, and better specificity when compared with TBUT and Schirmer's test results. ${ }^{10}$ The higher the severity of DED, the greater the correlation between tear osmolarity and other diagnostic tests; ${ }^{8}$ this result may indicate that other diagnostic tests are less sensitive to mild DED diagnosis. Given the intermittency of disease severity in the mild dry eye patient, the performance of all diagnostic tests will be more variable in this population segment.

Some studies examined the correlation between tear osmolarity and other dry eye diagnostic tests. For instance, meibomian gland dysfunction may not increase tear osmolarity, as demonstrated in one study. ${ }^{17}$ One explanation for this is that meibomian gland dysfunction alone may not be sufficient at overwhelming the homeostatic control in most patients. Examining all such studies in the present review, there is an indication that osmolarity is correlated with some other diagnostic tests, but the correlation is less apparent when looking only at those studies rated moderate quality or higher. One factor here is that the general correlation between objective tests and subjective tests for dry eye is poor. ${ }^{1}$ This issue is likely due to the multiple etiologies and presentations of DED; when particular tests are specific to one etiology, then there may be a lack of overall correlation. ${ }^{1}$

Like other diagnostic signs, tear osmolarity may not correlate with symptoms in a general population, ${ }^{18}$ although it has been shown to correlate over time with effective therapy, as described in the "Pharmacological effects and treatment" section of the present review. Dry eye symptoms can be non-specific or can be a result of a psychiatric disorder such as depression or post-traumatic stress disorder; both of these conditions increased dry eye symptoms but were not associated with other dry eye signs such as increased C-reactive protein or tear osmolarity. ${ }^{19}$ One study ${ }^{9}$ found that for the majority $(92 \%$, or $23 / 25)$ of patients, when the patient was symptomatic, his or her maximum tear osmolarity 
was $>308 \mathrm{mOsm} / \mathrm{L}$, and when the patient was asymptomatic, his or her maximum tear osmolarity was $<308 \mathrm{mOsm} / \mathrm{L}$. In the same study, ${ }^{9}$ a minority of patients $(8 \%$, or $2 / 25)$ had increased tear osmolarity and no symptoms or low tear osmolarity and symptoms; this result may be due to them having only mild DED in the former case, and low osmolarity due to a condition other than DED in the latter case. This study $^{9}$ concluded that increased tear osmolarity is likely a precursor for dry eye complaints, despite the lack of correlation between tear osmolarity and dry eye symptoms.

\section{Factors affecting tear osmolarity}

Certain factors, diseases, or drugs have been noted to be associated with DED and increased tear osmolarity. It is likely that not all patients exposed to the same external factors, diseases, or drugs will have dry eyes or increased tear osmolarity. Such reactions will be a function of the individual's response to these stresses and whether or not their eyes are able to adjust.

\section{External factors}

\section{Environmental factors}

The effect of external factors such as humidity on tear osmolarity is not clear. In one study, a high degree of variability in tear osmolarity was evident in "normal" subjects exposed to low relative humidity of $20 \%$ for 10 minutes..$^{20}$ Another study found that exposure to humidity of $5 \%$ for 2 hours did not increase or result in more variability in tear osmolarity. ${ }^{21}$ Both studies included subjects who were using artificial tears before the study, although they discontinued use more than 1 hour in advance of testing. One study did not specify the type of artificial tear used, and the other did not state the airflow velocity. Such differences may account for the conflicting results. ${ }^{20,21}$ In addition, the use of less sensitive diagnostic tests may have resulted in the inclusion of some mild dry eye patients in the normal group, which would have further confounded results. Further research pertaining to the effects of environmental factors on tear osmolarity appears warranted.

\section{Contact lens wear}

The literature is divided over whether or not contact lens wear increases ${ }^{2,22,23}$ or has no effect on tear osmolarity. ${ }^{10,24,25}$ Where osmolarity was measured in some of these studies, ${ }^{10,24}$ there was an appropriate delay between contact lens removal and osmolarity measurement. The differences in reported results are likely a function of the wearer's ability to maintain homeostasis of their tear film, overcoming the drying effect of contact lenses. ${ }^{10}$

\section{Surgery}

It appears that certain procedures may influence tear osmolarity more than others. In a recent 2013 article, no change in tear osmolarity or any other dry eye diagnostic test was observed after refractive surgery, despite a decrease in corneal sensitivity. ${ }^{26}$ After cataract surgery, tear osmolarity has been noted to increase. ${ }^{27}$ The difference here may be explained by the subjects' ages; average age was 26 years in the refractive surgery study ${ }^{26}$ and 71 years in the cataract surgery study. ${ }^{27}$ Older patients may take longer to recover from surgically induced ocular trauma. ${ }^{27}$ Trabeculectomy surgery performed on a patient population with an average age of 71 years also had higher tear osmolarity than a control group; this result was attributed to the presence of the bleb, the use of mitomycin $\mathrm{C}$ (which may cause epithelial damage), or the residual effects of long-term use of glaucoma medications before surgery. ${ }^{28}$ No difference in tear osmolarity was noted between the eye that underwent eyelid reconstruction surgery and the un-operated eye of the same patient; this result may be related with corrective tearing, as evidenced by the higher Schirmer's test results in the operated eye. ${ }^{29}$

\section{Ocular and systemic conditions}

Table 4 shows studies that investigated the effect of various ocular and systemic conditions on tear osmolarity. Of the systemic conditions, diabetes was found to increase tear osmolarity. ${ }^{30,31}$ An increase in tear osmolarity was correlated with an increase in diabetes duration. The relation between diabetes and increased tear osmolarity is most likely due to a decrease in the amount of aqueous secretion as a result of

Table 4 Reported association of osmolarity with dry eye-related disease

\begin{tabular}{lll}
\hline Disease name & $\begin{array}{l}\text { Increased } \\
\text { osmolarity }\end{array}$ & $\begin{array}{l}\text { No increase in } \\
\text { osmolarity }\end{array}$ \\
\hline Sjögren's syndrome & 30 \\
Graft-versus-host-disease & 30 & \\
Diabetes mellitus; with and without & 30,31 \\
retinopathy & & \\
Medicated and post-trabeculectomy & 28 \\
Both eyes in unilateral herpes keratitis & 41 & \\
Disease activity in fibromyalgia & 33 & \\
Traumatic brain injury & 34 & \\
Pterygium/pterygium re-occurrence & 39 & \\
Pseudoexfoliation syndrome & 38 & \\
Thyroid ophthalmopathy/increased & 2,32 & 36 \\
palpebral fissure & & 40 \\
Polycystic ovary syndrome & & 42 \\
Keratoconus & & \\
Nasolacrimal obstruction & & \\
\hline
\end{tabular}

Note: Numbers are article reference numbers. 
injury to the lacrimal gland, the small blood vessels of the lacrimal gland, and/or the corneal nerve. ${ }^{31}$ Thyroid disease that results in an increase in palpebral aperture and proptosis has also been reported to significantly increases tear osmolarity when compared to a control. ${ }^{32}$ Increased pain sensation, as evident in patients with fibromyalgia, was related to increased tear osmolarity. ${ }^{33}$ Traumatic brain injury patients had higher tear osmolarity values than a healthy control group. ${ }^{34}$

Patients with increased tear osmolarity may also be dehydrated, so water intake may be an important consideration for dry eye diagnosis and treatment. ${ }^{35}$ An increase in estrogen and/or progesterone (in the form of birth control pills) ${ }^{25}$ or the excess of androgens (as noted in patients with polycystic ovary syndrome $)^{36}$ seemed to have no effect on tear osmolarity. Another study found that low levels of 17-beta estradiol, estrone, and testosterone were associated with increased tear osmolarity; treatment with phytoestrogen decreased tear osmolarity when compared to a control group. ${ }^{37}$ More studies in this area appear warranted to further understand the correlation between sex hormones and tear osmolarity; adequate control of hydration or measurement of hydration status may be important in such studies.

Different ocular conditions also seem to have different effects on tear osmolarity (Table 4). For instance, eyes with pseudoexfoliation syndrome, a condition that is thought to alter goblet cell activity and mucin production, have been reported to have increased tear osmolarity when compared to a control group. ${ }^{38}$ Patients with pterygia, a predominantly inflammatory condition, also show increased tear osmolarity when compared with a control group. ${ }^{39}$ Keratoconus has been demonstrated to reduce corneal sensitivity, but tear osmolarity was similar to a control group. The reason for this similarity is not clear, though it may be that keratoconus is not generally clinically considered an inflammatory disease. ${ }^{40}$ Herpetic keratitis was associated with higher tear osmolarity in both the affected and unaffected eyes when compared to a control group; the reason the unaffected eye had higher tear osmolarity may be due to the type of keratitis. ${ }^{41}$ Patients with nasolacrimal duct obstruction are likely to compensate by decreasing tear production, resulting in a tear osmolarity value similar to a control group. ${ }^{42}$

\section{Pharmacological effects and treatment}

Table 5 summarizes the findings of different studies on the effect of certain drugs on tear osmolarity. The use of oral mucolytics, often to treat respiratory conditions, increases tear osmolarity. This increase is most likely due to alterations to the mucin layer of the tear film. ${ }^{43}$ Glaucoma medications
Table 5 Reported osmolarity changes with dry eye treatment

\begin{tabular}{lll}
\hline Treatment & \multicolumn{2}{l}{ Tear osmolarity } \\
\cline { 2 - 3 } & Reduction & No reduction \\
\hline $\begin{array}{l}\text { Anti-inflammatory medication } \\
\text { (cyclosporine/Restasis }^{\circledR} \text { ) }\end{array}$ & 49 & 48,50 \\
$\begin{array}{l}\text { Lubricating eyedrops/artificial tears } \\
\text { Phytoestrogen (steroid hormone) }\end{array}$ & $20,44,45$ & 16 \\
Oral contraceptive pills & 37 & \\
Oral mucolytics & & 25 \\
\hline
\end{tabular}

Note: Numbers are article reference numbers.

increased tear osmolarity, perhaps due to the preservatives, while such medications did not have a significant effect on TBUT or Schirmer's test results. ${ }^{28}$ Artificial tears have been noted by several studies to decrease tear osmolarity, ${ }^{20,44,45}$ but one study found no correlation between tear osmolarity and the use of artificial tears. ${ }^{16}$ The latter study did not disclose the type of artificial tear used. This may be an important factor, because the type of eye drop can impact tear osmolarity. ${ }^{45}$ For instance, lower osmolarity eye drops have been associated with lower tear osmolarity. ${ }^{46,47}$ It has been noted that the decrease in osmolarity observed with the use of artificial tears may be comparable to the effects of heat and massage application to the eyelids using a thermal massager. ${ }^{44}$ The effect of anti-inflammatory medication on tear osmolarity is less clear, especially because the studies evaluating this effect suffer from limitations such as small sample size and the lack of a control group or randomization. ${ }^{48-50}$ In one recent randomized, double-blind, parallel study in Finland, osmolarity was observed to increase through the dry winter months. ${ }^{51}$ Participants taking oral sea buckthorn oil, containing n-3 and n-6 fatty acids and antioxidants, had less of an increase in tear osmolarity when compared to a control group, presumed to have been a function of the oil's antiinflammatory mechanism. ${ }^{51}$

\section{Discussion}

A systematic review of 164 peer-reviewed articles related to the diagnostic value of tear osmolarity found that $72 \%$ of them have a positive impression of the value of tear osmolarity as a diagnostic tool for DED. These results were largely independent of financial interest and article quality rating.

There were not as many studies graded high or moderate as might be expected in a review of the literature of this type. It is worth noting that the grading systems used in the current review are typically applied to therapeutic trials where a gold standard control often exists. Dry eye is a multifactorial disease with no clear gold standard diagnostic test, so randomized masked trials and comparisons to a relevant control 
are more difficult to design. This is a recognized limitation of using these grading systems.

Performing tear osmolarity testing in a clinical setting appears to be more feasible with the availability of new instruments such as the TearLab ${ }^{\mathrm{TM}}$ Osmolarity System. Reflex tearing is not a concern when tear osmolarity is collected as per the label instructions. ${ }^{3,5,9}$ Test results have been shown to be repeatable and accurate, with good sensitivity and specificity. They appear to be better than other commonly used diagnostic tests, especially in the early stages of the disease. ${ }^{8,10,12,13}$ Correlations between different diagnostic tests remain an issue, but the lack of correlation is not surprising given the multifactorial nature of DED and the fact that different diagnostic tests reveal different aspects of the disease. ${ }^{1}$

The seemingly inconsistent threshold values reported in the literature may be a reflection of the disease's characteristic of tear film instability. It may also be due to the difference in disease severity of the tested groups, given the strong correlation between tear osmolarity and disease severity. ${ }^{9-11}$ The more severe the DED, the higher the threshold and the greater the variability in the tear osmolarity value. ${ }^{9}$ The currently agreed-upon value that discriminates between healthy and dry eyes is when the higher tear film osmolarity value of the two eyes is $308 \mathrm{mOsm} / \mathrm{L} .^{5,10}$ As with any diagnostic tool, interpretation must be based on the complete clinical picture, including other diagnostic tests that might be helpful in determining the dry eye etiology. ${ }^{10}$

Certain commonly encountered external factors such as contact lens wear may or may not increase tear osmolarity, depending on the individual response. ${ }^{2,24}$ The impact of environmental factors, such as temperature, humidity, and airflow on tear osmolarity appears unclear, as is the effect of sex hormones; these factors would benefit from further investigation. $^{20,21,25,36,37}$ The effect of ocular surgery on tear osmolarity may be partially dependent on the patient's age, the type of surgery performed, and the ability of the eye to recover. ${ }^{26-29}$ Systemic conditions commonly believed to result in dry eye, such as dehydration, diabetes, and thyroid ophthalmopathy, have been shown to increase tear osmolarity, as expected. ${ }^{31,32,35}$ Ocular conditions, such as herpetic keratitis, pterygia, and pseudoexfoliation syndrome, have also been demonstrated to increase tear osmolarity. ${ }^{38,39,41}$ Keratoconus, largely viewed clinically as a non-inflammatory condition, was not associated with increased tear osmolarity. ${ }^{40}$ Some pharmaceuticals, such as mucin-altering drugs and glaucoma medications, appear to increase tear osmolarity, while others, such as artificial tears, likely lower tear osmolarity. ${ }^{20,28,43}$ Research into the effect of anti-inflammatory medications on tear osmolarity has produced varied results; the topic deserves further investigation. ${ }^{48,49,51}$

There are limitations in any review of this nature, and consequently to any of our comments related to the factors associated with osmolarity. By confining the review to "tear osmolarity", related discussions of some of the dry eye issues (such as the effect of hormones) in some papers will have been missed. Additionally, in limiting the review to more recent papers, some of the foundational work in this field has been omitted.

\section{Conclusion}

In summary, the findings in the articles evaluated in the present review appear to confirm the central role of increased tear osmolarity in the pathophysiology of DED, as described by the DEWS. ${ }^{2}$ The majority of the studies reviewed here, and more specifically those rated as moderate or high quality, support the use of tear osmolarity as a tool to diagnose, grade severity, and track therapeutic response in DED.

\section{Acknowledgment}

The literature review and preparation of this manuscript was supported with funding to Science in Vision, Akron, NY, USA from TearLab Corporation, San Diego, CA, USA.

\section{Disclosure}

CJ Rapuano is a consultant for TearLab Corporation, but received no financial support for this work. No author has any proprietary or financial interest in the products or methods discussed. The authors report no other conflicts of interest in this work.

\section{References}

1. Sullivan BD, Crews LA, Messmer EM, et al. Correlations between commonly used objective signs and symptoms for the diagnosis of dry eye disease: clinical implications. Acta Ophthalmol. 2014;92(2): $161-166$.

2. The Definition and Classification Subcommittee of the International Dry Eye WorkShop. The definition and classification of dry eye disease: report of the Definition and Classification Subcommittee of the International Dry Eye WorkShop (2007). Ocul Surf. 2007;5(2):75-92.

3. Tomlinson A, McCann LC, Pearce EI. Comparison of human tear film osmolarity measured by electrical impedance and freezing point depression techniques. Cornea. 2010;29(9):1036-1041.

4. Gokhale M, Stahl U, Jalbert I. In situ osmometry: validation and effect of sample collection technique. Optom Vis Sci. 2013;90(4):359-365.

5. Jacobi C, Jacobi A, Kruse FE, Cursiefen C. Tear film osmolarity measurements in dry eye disease using electrical impedance technology. Cornea. 2011;30(12):1289-1292.

6. Levels of evidence: Grading of Recommendations Assessment, Development, and Evaluation (GRADE) [webpage on the Internet]. Hoboken, NJ: John Wiley \& Sons, Inc; 2015 [cited August 14, 2015]. Available from: http://www.essentialevidenceplus.com/product/ebm_loe cfm?show=grade. Accessed September 16, 2015. 
7. Levels of evidence: key to interpretation of practice guidelines [webpage on the Internet]. Hoboken, NJ: John Wiley \& Sons, Inc; 2015 [cited August 14, 2015]. Available from: http://www.essentialevidenceplus.com/ product/ebm_loe.cfm?show=guidelines. Accessed September 16, 2015.

8. Versura P, Profazio V, Campos EC. Performance of tear osmolarity compared to previous diagnostic tests for dry eye diseases. Curr Eye Res. 2010;35(7):553-564.

9. Keech A, Senchyna M, Jones L. Impact of time between collection and collection method on human tear fluid osmolarity. Curr Eye Res. 2013; 38(4):428-436.

10. Lemp MA, Bron AJ, Baudouin C, et al. Tear osmolarity in the diagnosis and management of dry eye disease. Am J Ophthalmol. 2011;151(5): 792-798.e1.

11. Sullivan BD, Whitmer D, Nichols KK, et al. An objective approach to dry eye disease severity. Invest Ophthalmol Vis Sci. 2010;51(12): 6125-6130.

12. Tomlinson A, Khanal S, Ramaesh K, Diaper C, McFadyen A. Tear film osmolarity: determination of a referent for dry eye diagnosis. Invest Ophthalmol Vis Sci. 2006;47(10):4309-4315.

13. Khanal S, Tomlinson A, Diaper CJ. Tear physiology of aqueous deficiency and evaporative dry eye. Optom Vis Sci. 2009;86(11):1235-1240.

14. Khanal S, Tomlinson A, McFadyen A, Diaper C, Ramaesh K. Dry eye diagnosis. Invest Ophthalmol Vis Sci. 2008;49(4):1407-1414.

15. Szalai E, Berta A, Szekanecz Z, Szûcs G, Módis L Jr. Evaluation of tear osmolarity in non-Sjögren and Sjögren syndrome dry eye patients with the TearLab system. Cornea. 2012;31(8):867-871.

16. Messmer EM, Bulgen M, Kampik A. Hyperosmolarity of the tear film in dry eye syndrome. Dev Ophthalmol. 2010;45:129-138.

17. Meadows JF, Ramamoorthy P, Nichols JJ, Nichols KK. Development of the 4-3-2-1 meibum expressibility scale. Eye Contact Lens. 2012;38(2): $86-92$.

18. Amparo F, Jin Y, Hamrah P, Schaumberg DA, Dana R. What is the value of incorporating tear osmolarity measurement in assessing patient response to therapy in dry eye disease? Am J Ophthalmol. 2014; 157(1):69-77.e2.

19. Fernandez CA, Galor A, Arheart KL, et al. Dry eye syndrome, posttraumatic stress disorder, and depression in an older male veteran population. Invest Ophthalmol Vis Sci. 2013;54(5):3666-3672.

20. Tomlinson A, Madden LC, Simmons PA. Effectiveness of dry eye therapy under conditions of environmental stress. Curr Eye Res. 2013;38(2): 229-236.

21. López-Miguel A, Tesón M, Martín-Montañez V, et al. Dry eye exacerbation in patients exposed to desiccating stress under controlled environmental conditions. Am J Ophthalmol. 2014;157(4):788-798.e2.

22. Nichols JJ, Sinnott LT. Tear film, contact lens, and patient-related factors associated with contact lens-related dry eye. Invest Ophthalmol Vis Sci. 2006;47(4):1319-1328.

23. Miller WL, Doughty MJ, Narayanan S, et al. A comparison of tear volume (by tear meniscus height and phenol red thread test) and tear fluid osmolality measures in non-lens wearers and in contact lens wearers. Eye Contact Lens. 2004;30(3):132-137.

24. Muselier-Mathieu A, Bron AM, Mathieu B, et al. Ocular surface assessment in soft contact lens wearers; the contribution of tear osmolarity among other tests. Acta Ophthalmol. 2014;92(4):364-369.

25. Chen SP, Massaro-Giordano G, Pistilli M, Schreiber CA, Bunya VY. Tear osmolarity and dry eye symptoms in women using oral contraception and contact lenses. Cornea. 2013;32(4):423-428.

26. Demirok A, Ozgurhan EB, Agca A, et al. Corneal sensation after corneal refractive surgery with small incision lenticule extraction. Optom Vis Sci. 2013;90(10):1040-1047.

27. Khanal S, Tomlinson A, Esakowitz L, et al. Changes in corneal sensitivity and tear physiology after phacoemulsification. Ophthalmic Physiol Opt. 2008;28(2):127-134.

28. Lee SY, Wong TT, Chua J, Boo C, Soh YF, Tong L. Effect of chronic anti-glaucoma medications and trabeculectomy on tear osmolarity. Eye (Lond). 2013;27(10):1142-1150.
29. Klein-Theyer A, Horwath-Winter J, Dieter FR, Haller-Schober EM, Riedl R, Boldin I. Evaluation of ocular surface and tear film function following modified Hughes tarsoconjunctival flap procedure. Acta Ophthalmol. 2014;92(3):286-290.

30. Alves M, Reinach PS, Paula JS, et al. Comparison of diagnostic tests in distinct well-defined conditions related to dry eye disease. PLoS One. 2014;9(5):e97921.

31. Sağdık HM, Ugurbas SH, Can M, et al. Tear film osmolarity in patients with diabetes mellitus. Ophthalmic Res. 2013;50(1):1-5.

32. Iskeleli G, Karakoc Y, Abdula A. Tear film osmolarity in patients with thyroid ophthalmopathy. Jpn J Ophthalmol. 2008;52(4):323-326.

33. Türkyilmaz K, Türkyilmaz AK, Kurt EE, Kurt A, Öner V. Dry eye in patients with fibromyalgia and its relevance to functional and emotional status. Cornea. 2013;32(6):862-866.

34. Cockerham GC, Lemke S, Glynn-Milley C, Zumhagen L, Cockerham KP. Visual performance and the ocular surface in traumatic brain injury. Ocul Surf. 2013;11(1):25-34.

35. Walsh NP, Fortes MB, Raymond-Barker P, et al. Is whole-body hydration an important consideration in dry eye? Invest Ophthalmol Vis Sci. 2012;53(10):6622-6627.

36. Gonen T, Celik C, Oznur M, et al. Tear osmolarity and ocular surface changes in patient with polycystic ovary syndrome. Curr Eye Res. 2013; 38(6):621-625.

37. Mah F, Milner M, Yiu S, Donnenfeld E, Conway TM, Hollander DA. PERSIST: Physician's Evaluation of Restasis $\left({ }^{\circledR}\right)$ Satisfaction in Second Trial of topical cyclosporine ophthalmic emulsion $0.05 \%$ for dry eye: a retrospective review. Clin Ophthalmol. 2012;6:1971-1976.

38. Öncel BA, Pinarci E, Akova YA. Tear osmolarity in unilateral pseudoexfoliation syndrome. Clin Exp Optom. 2012;95(5):506-509.

39. Julio G, Lluch S, Pujol P, Alonso S, Merindano D. Tear osmolarity and ocular changes in pterygium. Cornea. 2012;31(12):1417-1421.

40. Cho KJ, Mok JW, Choi MY, Kim JY, Joo CK. Changes in corneal sensation and ocular surface in patients with asymmetrical keratoconus. Cornea. 2013;32(2):205-210.

41. M'Garrech M, Rousseau A, Kaswin G, et al. Impairment of lacrimal secretion in the unaffected fellow eye of patients with recurrent unilateral herpetic keratitis. Ophthalmology. 2013;120(10):1959-1967.

42. Stahl U, Francis IC, Stapleton F. Prospective controlled study of vapor pressure tear osmolality and tear meniscus height in nasolacrimal duct obstruction. Am J Ophthalmol. 2006;141(6):1051-1056.

43. Kim D, Kim HJ, Hyon JY, Wee WR, Shin YJ. Effects of oral mucolytics on tear film and ocular surface. Cornea. 2013;32(7):933-938.

44. Lee JE, Kim NM, Yang JW, Kim SJ, Lee JS, Lee JE. A randomised controlled trial comparing a thermal massager with artificial teardrops for the treatment of dry eye. Br J Ophthalmol. 2014;98(1):46-51.

45. Iester M, Orsoni GJ, Gamba G, et al. Improvement of the ocular surface using hypotonic $0.4 \%$ hyaluronic acid drops in keratoconjunctivitis sicca. Eye (Lond). 2000;14(Pt 6):892-898.

46. Cömez AT, Tufan HA, Kocabiyık O, Gencer B. Effects of lubricating agents with different osmolalities on tear osmolarity and other tear function tests in patients with dry eye. Curr Eye Res. 2013;38(11): 1095-1103.

47. Montani G. Intrasubject tear osmolarity changes with two different types of eyedrops. Optom Vis Sci. 2013;90(4):372-377.

48. Bunya VY, Langelier N, Chen S, Pistilli M, Vivino FB, MassaroGiordano G. Tear osmolarity in Sjögren syndrome. Cornea. 2013;32(7): 922-927.

49. Sullivan BD, Crews LA, Sönmez B, et al. Clinical utility of objective tests for dry eye disease: variability over time and implications for clinical trials and disease management. Cornea. 2012;31(9):1000-1008.

50. Di Tommaso C, Valamanesh F, Miller F, et al. A novel cyclosporin a aqueous formulation for dry eye treatment: in vitro and in vivo evaluation. Invest Ophthalmol Vis Sci. 2012;53(4):2292-2299.

51. Larmo PS, Järvinen RL, Setälä NL, et al. Oral sea buckthorn oil attenuates tear film osmolarity and symptoms in individuals with dry eye. J Nutr. 2010;140(8):1462-1468. 
Clinical Ophthalmology

\section{Publish your work in this journal}

Clinical Ophthalmology is an international, peer-reviewed journal covering all subspecialties within ophthalmology. Key topics include: Optometry; Visual science; Pharmacology and drug therapy in eye diseases; Basic Sciences; Primary and Secondary eye care; Patien Safety and Quality of Care Improvements. This journal is indexed on

PubMed Central and CAS, and is the official journal of The Society of Clinical Ophthalmology (SCO). The manuscript management system is completely online and includes a very quick and fair peer-review system, which is all easy to use. Visit http://www.dovepress.com/ testimonials.php to read real quotes from published authors. 